\title{
Microstructure and Performance of Mg-substituted $\beta$-TCP Porous Ceramics
}

\author{
Yunhai Ma \\ 1.College of Biological and Agricultural Engineering, \\ Jilin University (Nanling Campus); \\ 2.Key Laboratory of Bionic Engineering, Ministry of \\ Education, Jilin University, \\ Changchun 130021, China; \\ e-mail: $\underline{\text { myh@jjlu.edu.cn }}$
}

\section{Wenbo Shang}

1.College of Biological and Agricultural Engineering, Jilin University (Nanling Campus);

2.Key Laboratory of Bionic Engineering, Ministry of

Education, Jilin University,

Changchun 130021, China ;

e-mail: shangwenbo123@163.com

\section{Xueying Fan}

1.College of Biological and Agricultural Engineering, Jilin University (Nanling Campus);

2.Key Laboratory of Bionic Engineering, Ministry of Education, Jilin University,

Changchun 130021, China;

e-mail: 390916495@qq.com

\author{
Zhihui Gao \\ 1.College of Biological and Agricultural Engineering, \\ Jilin University (Nanling Campus); \\ 2.Key Laboratory of Bionic Engineering, Ministry of \\ Education, Jilin University, \\ Changchun 130021, China ; \\ e-mail: 570814141@qq.com
}

Hubiao Wang

1.College of Biological and Agricultural Engineering, Jilin University (Nanling Campus);

2.Key Laboratory of Bionic Engineering, Ministry of Education, Jilin University, Changchun 130021, China ; e-mail: 616598148@qq.com

Xueman Luy*(Corresponding author)

1.College of Biological and Agricultural Engineering, Jilin University (Nanling Campus);

2.Key Laboratory of Bionic Engineering, Ministry of Education, Jilin University;

3.China-Japan Union Hospital of Jilin University

Changchun 130033, China;

e-mail: lv xueman@sina.com

Immersion test indicated that the Mg-substituted improved the performance of degradation apparently.

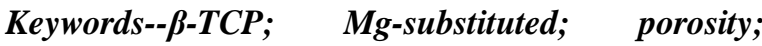
Microstructure; Immersion

\section{INTRODUCTION}

ceramics. The $6 \mathrm{~mol} . \% \mathrm{Mg}$-doped powders were fabricated by the method of gel-sol combustion with raw materials of $\mathrm{Ca}(\mathrm{NO3}) 2$, PBTC and $\mathrm{Mg}(\mathrm{NO3}) 2$. Mg-substituted $\beta$-TCP porous ceramics were obtained by molded-pressing with the foaming agent and the binder before calcined at $1000^{\circ} \mathrm{C}$. The mechanical properties, microstructure, immersion performance had been evaluated by means of mechanical testing machine, X-ray diffraction, scanning electron microscopy with EDS and immersion test. The compressive test showed that the compressive strength of $\mathrm{Mg}$-doped porous ceramics increased $10.5 \%$ from 5.92MPa to 6.54MPa compared with the pure porous scaffolds. The SEM Images demonstrated that the porosity of ceramic was about $65 \%$, the size of interconnect holes were ranging from 50 to $200 \mu \mathrm{m}$.
Calcium Phosphate $\left(\mathrm{Ca}_{3}\left(\mathrm{PO}_{4}\right)_{2}\right)$ ceramics have been indentified as important materials for bone reconstruction, such as beta-tricalcium phosphate ( $\beta$-TCP) and hydroxyapatite (HAp) [1,2]. In particular, the $\beta$-tricalcium phosphate is one of the most attractive biomaterials due to the biological properties mainly biocompatibility, bioactivity, biodegradability[3,4]. The inorganic composition of $\beta$-TCP is similar to that of bone tissue, after implanted $\beta$-TCP shows an excellent biodegradability. The dissolved calcium and phosphate ions can be used for the formation of new bone tissues. The $\beta$-TCP porous bioceramics provide support for the growth of new bone indicated the material with good osteoconductivity.

In recent investigates, porous ceramics which should have features such as high porosity along with 
micro-macropores and interconnected pore structutres. But the porous scaffolds show poor mechanical properties especially in bending strength and toughness[5]. How to improve the mechanical properties of $\beta$-TCP porous ceramics rised the attention of scholars. Some authors investigated that the substitution of ions found in natural bones showed positive functions in improving the biocompatibility and mechanical properties of $\beta$-TCP[6]. Yoshida et al. suggested that the sinterability of $\beta$-TCP is enhanced by the substitution of mono-and divalent metal ions[7]. $\mathrm{Mg}$ is the fourth major cation in human body and the second most prevalent intracellular cation, approximately $50-60 \%$ of the total amount of $\mathrm{Mg}$ is in bone tissue and only $1.0 \%$ is in the extracellular fluid[8,9]. It has been demonstrated that the mechanical properties has been improved effectively with the substitution of $\mathrm{Mg}$ [7-12].

The purpose of the study was to investigate the influence of $\mathrm{Mg}$-instituted $\beta$-TCP porous ceramics crystal structure and in vitro degradation in SBF and the compressive strength. In this study, pure and Mg-substituted $\beta$-TCP powders would be synthesised by the the gel-sol combustion method. Then the $\beta$-TCP porous bioceramics would be sintered at $1000^{\circ} \mathrm{C}$ with the pore-foaming agent and high temperature adhesive bondings added in.

\section{MATERIALS AND METHODS}

\section{A. Materials Preparation}

The precursors of $\beta$-tricalcium phosphate and $\mathrm{Mg}$ substitued $\beta$-tricalcium phosphate had been made in fuming cupboard at $80^{\circ} \mathrm{C}$ under magnetic stirring. It has been reported that magnesium ions might substitute calcium site in the tricalcium phosphate lattice. The raw materials used for making precursors of $\beta$-TCP were calcium nitrate tetrahydrate (reagent grade, Chemical reagent Ltd, Co, Beijing) and 2-phosphonobutane -1,2,4tricarboxylic acid (PBTC, 50wt\%, Taihe Water Treatment Ltd. Co, Shandong). Weighing the reactants according to the atomic ratio of calcium and phosphuros 1.5, putting the reactants into a beaker and adding some deionized water. Then the reaction would go on under magnetic stirring with the reaction temperature controlled between $80^{\circ} \mathrm{C}$ and $100^{\circ} \mathrm{C}$ for 3 hours in fuming cupboard.

As for precursors of $\mathrm{Mg}$-substitued $\beta$-tricalcium phosphate (Mg content $\sim$ the atomic ratio should be $[\mathrm{Mg} / \mathrm{Ca}+\mathrm{Mg}=6 \mathrm{~mol} . \%])$, magnesium nitrate hexahydrate (reagent grade, Beijing) was added into the reaction, also the atomic ratio should be maintained at $(\mathrm{Ca}+\mathrm{Mg} / \mathrm{P}=1.5)$. Then drying the precursors at $160^{\circ} \mathrm{C}$ in oven for 4 hours. Finally the precursors would be calcined at $1000^{\circ} \mathrm{C}$ to get the $\mathrm{Mg}$-substituted $\beta$-tricalcium phosphate powders for further used.

In order to obtain $\mathrm{Mg}$-substituted $\beta$-TCP porous ceramics, the stearic acid[13] was used as pore-foaming agent and the polyvinyl alcohol (PVA) was chose as the binders. Mix the raw materials into the mold homogeneously and mold pressing at $80 \mathrm{MPa}$ with a press machine. Then the samples were further thermal treated at $1000^{\circ} \mathrm{C}$ in the furnace.

\section{B. Particle Size Measurement}

The particle size of Mg-substituted $\beta$-TCP powder was measured by BT-9300 type laser particle size distribution.

\section{Porosity Measurement}

The porosity of Mg-substituted $\beta$-TCP porous ceramic was measured by the liquid discharge method. At first, the porous scaffold was weighed as $M$ after dried to constant weight in the oven. Put some ethanol for the volume of $\mathrm{V}_{1}$ into the measuring cylinder, then the Mg-substituted $\beta$-TCP porous ceramic was submerged into the alcohol for 15 minutes, the volume would be maintained of $\mathrm{V}_{2}$ until there exist no bubble. Finally, take the sample out carefully and the volume of the ethanol remained in the cylinder was $\mathrm{V}_{3}$. The porosity was calculated according to the formula below:

$$
\varepsilon=\frac{V 1-V 3}{V 2-V 3} \times 100 \%
$$

Where $\varepsilon$ is the porosity, the volume of sample is $\mathrm{V}$ $\left(\mathrm{V}=\mathrm{V}_{2}-\mathrm{V}_{3}\right)$; Three parallel samples were taken for every porous ceramics. Finally, the porosity value was achieved.

\section{Microstructure Characterization}

X-ray diffraction analysis was used to identify the crystalline phases of Mg-substituted $\beta$-TCP powder over a $2 \theta$ range of $10^{\circ}-70^{\circ}$ at a speed of $10^{\circ}$ per minute in the $\mathrm{X}$-ray diffractometer. SEM was employed to observe the microstructural features and the pore size of Mg-substituted $\beta$-TCP porous ceramic.

\section{E. Compression Test}

The compression test was conducted on a QT-1186 type tensile and compression testing machine with the limit load as $1000 \mathrm{~N}$. The test went on at the speed of $1 \mathrm{~mm}$ per minute and the samples were prepared with the size of $\varphi 10 \mathrm{~mm} \times 20 \mathrm{~mm}$. Three identical samples were used for the compressive test.

\section{F. Immersion Test}

The immersion test was carried out in simulated body solution $(\mathrm{SBF})[14]$ at the temperature of $36.8^{\circ} \mathrm{C}$. The $\mathrm{SBF}$ was prepared by dissolving a reagent-grade $\mathrm{NaCl}$, $\mathrm{KCl}, \mathrm{NaHCO}_{3}, \quad \mathrm{MgCl}_{2} \cdot 6 \mathrm{H}_{2} \mathrm{O}, \mathrm{CaCl}_{2}, \mathrm{KHPO}_{4}$ into deionized water and buffered at $\mathrm{pH}$ 7.4. The samples were prepared with the size of $\varphi 20 \mathrm{~mm} \times 10 \mathrm{~mm}$. After 28 days immersion, the samples were removed out of the solution, sightly washed with deionized water and dried in the oven for overnight. Then scanning electron microscopy (SEM) equipped with energy disperse spectrometer (EDS) was employed for the microstructure identification of the precipitate formation on the surfaces of the porous ceramics after soaking in SBF.

\section{RESULTS AND DISCUSSION}

\section{A.Particle Size of Mg-substituted $\beta$-TCP Powder}

Particle size of the Mg-substituted $\beta$-TCP powders was shown in table 1 . The median diameter was $11.17 \mu \mathrm{m}$ proved that the Mg-doped powder was micron grade. The table 1 clearly showed that D75 was $22.99 \mu \mathrm{m}$ meant that the diameter of most powders were less than $50 \mu \mathrm{m}$. Also the Fig 1 showed that the size of more than 96 percent powders were less than $35 \mu \mathrm{m}$ meet the requirement for 
TABLE 1. PARTICLE SIZE OF PHYSICAL PARAMETERS ABOUT Mg-SUBSTITUTED $\beta$-TCP POEDER

\begin{tabular}{ccccc} 
median diameter: $11.17 \mu \mathrm{m}$ & volume mean diameter: $15.11 \mu \mathrm{m}$ & surface mean diameter:4.55 $\mu \mathrm{m}$ & shading coefficient:20.67 \\
\hline specific surface area: $0.48 \mathrm{~m}^{2} / \mathrm{g}$ & material refractive index:1.520+0.100i & medium refractive index:1.333 & span:2.92 \\
\hline $\mathrm{D} 3: 0.94 \mu \mathrm{m}$ & $\mathrm{D} 6: 1.36 \mu \mathrm{m}$ & $\mathrm{D} 10: 1.93 \mu \mathrm{m}$ & $\mathrm{D} 16: 2.79 \mu \mathrm{m}$ & $\mathrm{D} 25: 4.3 \mu \mathrm{m}$ \\
\hline $\mathrm{D} 75: 22.99 \mu \mathrm{m}$ & $\mathrm{D} 84: 29.1 \mathrm{um}$ & $\mathrm{D} 90: 34.61 \mu \mathrm{m}$ & $\mathrm{D} 97: 45.54 \mu \mathrm{m}$ & $\mathrm{D} 98: 48.67 \mu \mathrm{m}$ \\
\hline
\end{tabular}

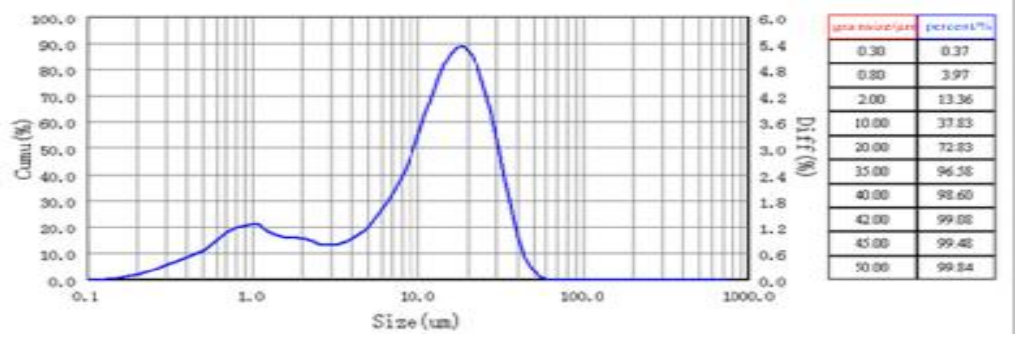

Figure 1. Particle size of powder distribution curve

\section{B. Microstructure of Mg-substituted $\beta$-TCP porous ceramics}

XRD analysis of Mg-substituted $\beta$-TCP porous ceramics were showed in Fig 2, the (a) showed that after calcined at $1000{ }^{\circ} \mathrm{C}$ there existed no impurities among the porous scaffolds, the characteristic peaks were obviously and no differences in the patterns were detected. However, the pattern (b) showed that compared with pure $\beta$-TCP porous ceramics the characteristic peaks of Mg-substituted scaffolds shifted to the right significantly. It should be that the redius of magnesium was $0.078 \mathrm{~nm}$ and also the redius of calcium was $0.106 \mathrm{~nm}$. The process of Mg-substituted should be magnesium replaced the cite of calcium in the crystal lattice causing the lattice distortion. From the Brag formula:

$$
\lambda=2 d \sin \theta
$$

Where $\lambda$ is the wavelength of incident X-rays which is known; $\theta$ is the angle of XRD diffraction peaks to be measured; $d$ is the interplanar crystal spacing. In the formula $\lambda$ is constant, Fig 2(b) showed the $\theta$ of Mg-substituted scaffolds became larger than pure $\beta$-TCP porous ceramics, so $\mathrm{d}$ would be smaller demonstrated that magnesium partly replaced the position of calcium in the lattice.

From the SEM microphotographs in Fig 3, it was evident that micro and mesopore structure were found in the surface of porous Mg-substituted $\beta$-TCP scaffolds. However, from Fig 3(b) hollow structure and fully interconnected geometry were successfully achieved since the foaming agent as stearic acid leaded to the formation of the porous scaffolds with open porosity and macropores ranging from 50 to $200 \mu \mathrm{m}$. The interconnected network structure were necessary for the circulation of body fluid and the bone tissue ingrowth and vascularization. The porosity of the Mg-substituted porous ceramics was nearly $65 \%$ and the size of holes would be controlled by the size of stearic acid. The large porosity would increase the surface area and the connection of the porous ceramics with the host bone. The gradient of the hole size was obtained by molded pressing, the gradient structure was in favour of the mechanical properties.

\section{Mechanical property of $M g$-substituted $\beta$-TCP porous ceramics}

Fig 4 showed the compressive curve of porous ceramic before and after $\mathrm{Mg}$-substituted. From the formula the compressive strength could be calculated:

$$
P=\frac{F \mathrm{c}}{S}
$$

Where $P$ was the compressive strength; $F c$ was the critical damage load; $S$ was the force area of the sample. From fig 4 it could be seen clearly that the damage load rised from $465 \mathrm{~N}$ before $\mathrm{Mg}$-doped to $513 \mathrm{~N}$ after Mg-doped. The force area was $7.85 \times 10^{-5} \mathrm{~mm}^{2}$, so the compressive improved 10.5 percent after $\mathrm{Mg}$-doped from $5.92 \mathrm{MPa}$ to $6.54 \mathrm{MPa}$. The result demonstrated that the $\mathrm{Mg}$ iron substituted improved the mechanical properties of porous ceramic obviously. 


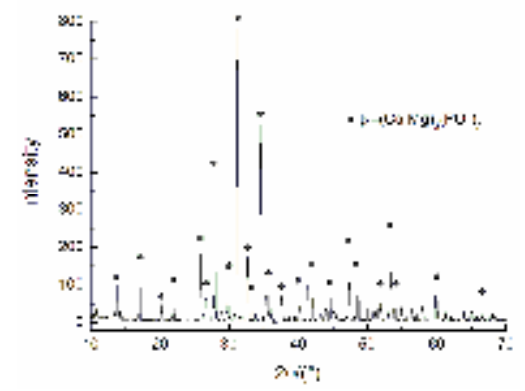

Figure 2. XRD patterns (a) Mg-substituted $\beta$-TCP porous ceramic

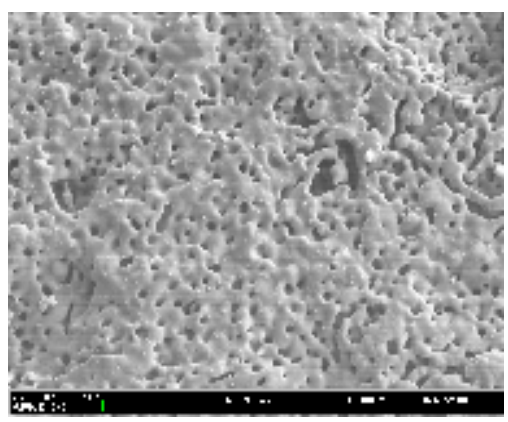

Figure 3. SEM Images (a) the surface of Mg-doped ceramic

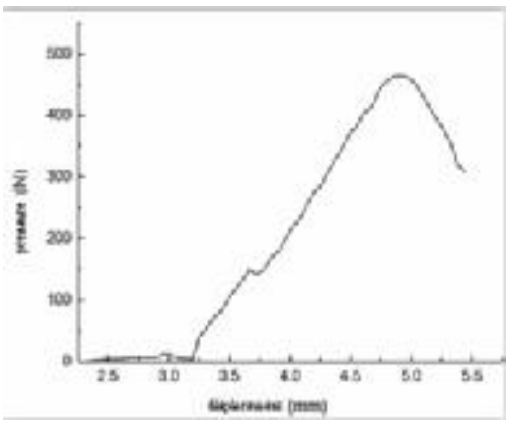

Figure 4. compressiom curve (a) before Mg-substituted porous ceramic

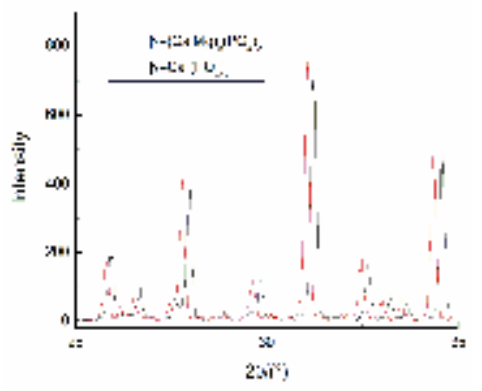

(b) before and after Mg-substituted

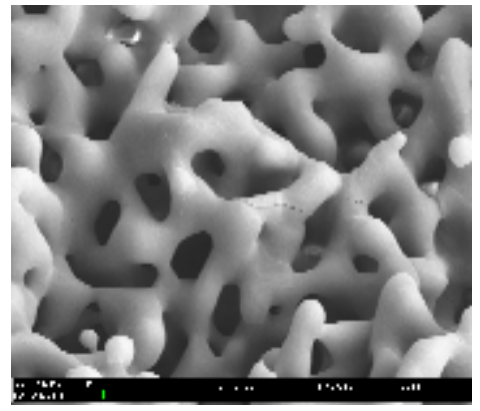

(b)the internal image of Mg-doped ceramic

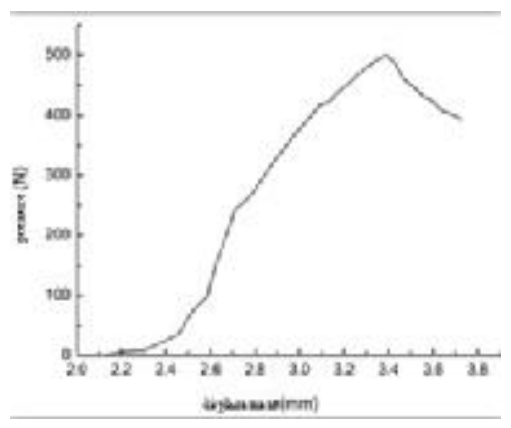

(b) after Mg-substituted porous ceramic

\section{Immersion property of $M g$-substituted $\beta$-TCP porous ceramics}

Fig 4 showed the SEM Images of Mg-substituted $\beta$-TCP porous ceramics before and after 28 days immersion in $\mathrm{SBF}$ solution at $36.8^{\circ} \mathrm{C}$. Fig 4 illustrated that some of the newly generated precipitate deposited on the surface of Mg-substituted $\beta$-TCP porous scaffolds. The porous scaffolds showed two different surfaces: a smooth surface before immersion and a surface with lots of small grain formed after immersion.

Fig 5 and Fig 6 showed the EDS patterns of Mg-substituted $\beta$-TCP porous ceramics before and after immersion. From the data in the pattern, it could be seen clearly that the atomic ratio of calcium and phosphate was 1.497 (almost 1.5 the target value of $\beta$-TCP) before immersion. However, after immersion the atomic ratio had increased to 1.626 (nearly 1.67 the desired value of hydroxyapatite). The change from fig 5 to fig 6 demonstrated that during the immersion the Mg-substituted $\beta$-TCP porous ceramics had dissolved in the SBF solution partly, at the same time the bone-like hydroxyapatite generated on the porous scaffolds surface. The magnesium ion substituted did in favour of the in vitro immersion. 

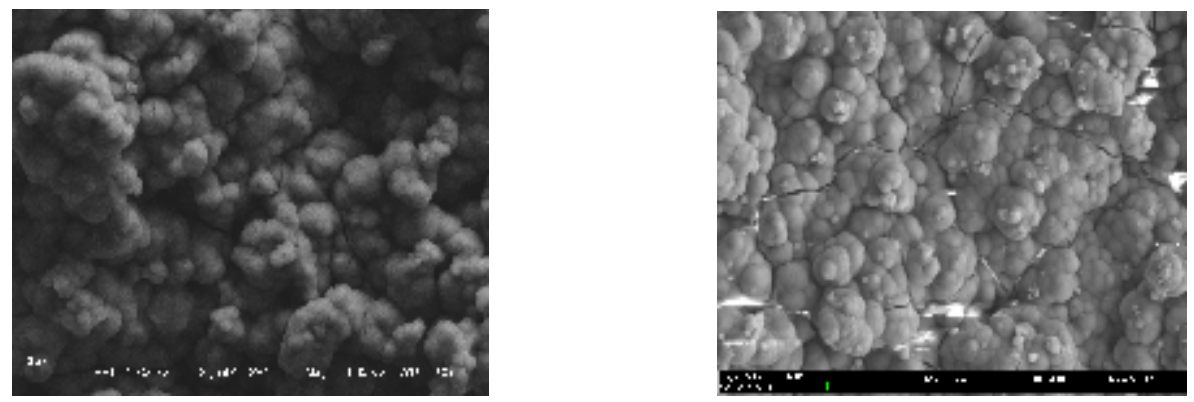

Figure 4. SEM Images for Mg-substituted $\beta$-TCP porous ceramics (a) before immersion (b)after immersion for 28 days
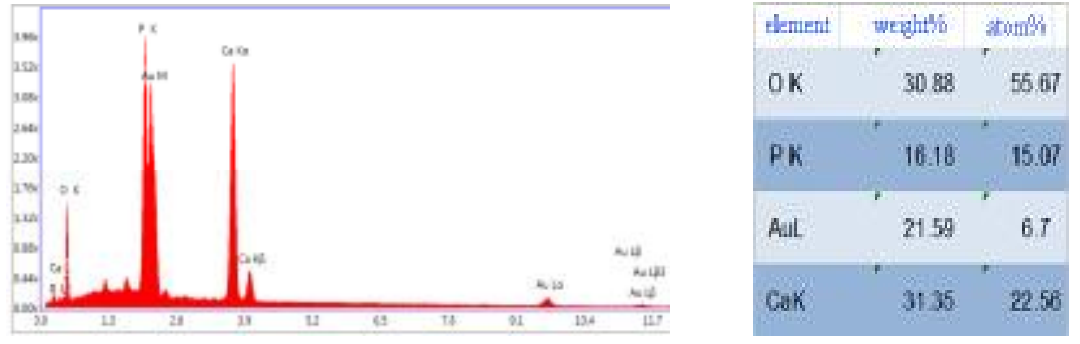

Figure 5. EDS patterns for Mg-substituted porous ceramics before immersion
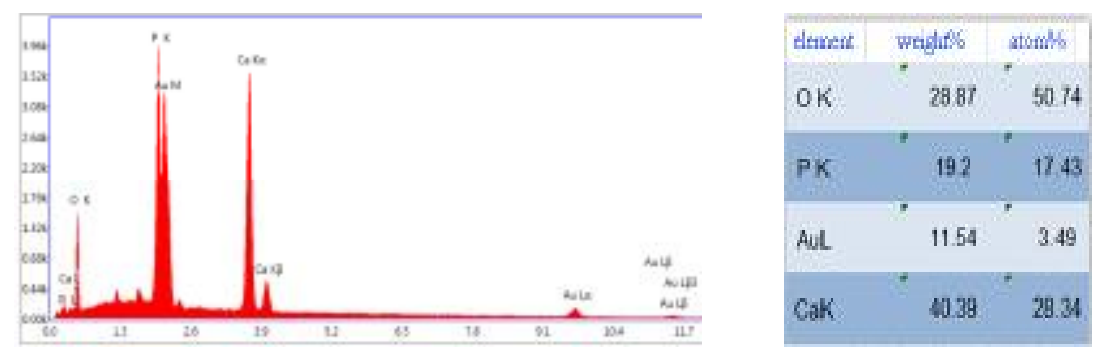

Figure 6. EDS patterns for Mg-substituted porous ceramics after immersion

\section{IV 、 CONCLUSION}

To study the properties of $6 \mathrm{~mol} . \% \mathrm{Mg}$-substituted of $\beta$-TCP porous ceramics, the gel-sol combustion method was employed to synthesis pure and Mg-doped powders. After calcined at $1000^{\circ} \mathrm{C}$ the size of Mg-doped $\beta$-TCP powders were at micro scale meet the requirment for further used. The compressive test indicated that after Mg-doped the compressive strength increased $10.5 \%$ compared to the pure $\beta$-TCP porous ceramics. During the in vitro immersion experiment the Mg-doped porous ceramics showed a good biodegradability, after partly dissolved in SBF solution there generated the bone-like hydroxyapatite. $\mathrm{Mg}$ irons substitution apparently improved the mechanical properties and degradation of $\beta$-TCP porous ceramics.

\section{ACKNOWLEDGMENT}

The authors would like to thank the National Natural Science Foundation of China (51075177, 51475205), Jilin Province Science and Technology Development Plan Item (Grant No. 20120716 ，20150519022JH and 20130101043JC).

\section{REFERENCES}

[1] Burg KJL, Porter S, Kellam JF. Biomaterial developments for bone tissue engineering. Biomaterials 2000;21(23):2347-59.

[2] Engin NO, Tas AC. Manufacture of macroporous calcium hydroxyapatite bioceramics. Journal of the European Ceramic Society 1999;19:2569-72.

[3] L.L. Hench, J Wilson. An Introduction to Bioceramics. World Scientific, London, U.K. 1993.

[4] H Yonezaki, T Hayashi, T Nakagawa, H Kurosawa, K Shibuya, K Ioku. Influence of surface microstructure on the reaction of the active ceramics in vivo. J Master. Sci: Mater. Med. 9 (1998) 381-384.

[5] F.-H. Lin, C.-J. Liao, K.-S. Chen, J.-S. Sun, C.-P. Lin. Petal-like apatite formed on the surface of tricalcium phosphate ceramic after soaking in distilled water. Biomaterial 22 (12) (2001) 2981-2992.

[6] Wang X, Dong LH, Ma XL, Zheng YF. Microstructure, mechanical property and corrosion behaviors of interpenetrating $\mathrm{C} / \mathrm{Mg}-\mathrm{Zn}-\mathrm{Mn}$ composite fabricated by suction casting. Mater Sci Eng C 2013;33:618-25.

[7] K. Yoshida, W.A. Kondo, H. Kita. Effect of substitutional monovalent and divalent metal ions on mechanically properties of $\beta$-tricalcium phosphate. J. Am. Ceram. Soc. 88 (2005) 2315-2318.

[8] Rude RK, Gruber HE. Magnesium deficiency and osteoporosis:animal and human observations. J Nutr Biochem 2004; $15: 710$.

[9] C. Ilaria, B. Alessandra. High thermally stable Mg-substituted tricalcium phosphate via precipitation[J]. Ceramics International. 37 (2011) 127-137. 
[10] Okuma T. Magnesium and bone strength. Nutrition 2001:17:679.

[11] M. Toriyama, S Kawamura, H. Nagae, K. Ishida. Effect of Mgo addition on bending strength of sintered $\beta$-tricalcium phosphate prepared by mechanochemical synthesis. J. Ceram. Soc. Jpn. (Yogyo-Kyokai-Shi) 95 (1987) 822-824 (in Japanese)

[12] K. Itatani, M. Takahashi, F.S. Howell, M. Aizawa. Effect of metal-oxdie addition on the sintering of $\beta$-tricalcium phosphate. $J$ Master. Sci: Mater. Med. 13(2002) 707-713.
[13] S.H Zhang, D.S. Xiong. Preparation and characterization of $\beta$-tricalcium phosphate porous ceramics[J]. Journal of nanjing university of science and technology. 29 (2005) 231-235.

[14] Lin Kai-li, Chang Jiang, Lu Jian-xi, et al. Fabrication and Characterization of $\beta-\mathrm{Ca} 3(\mathrm{P} 04) 2 / \mathrm{CaSi} 03$ composite bioceramics $[\mathrm{J}]$. Journal of Inorganic Materials, 2006, 21(6): 1429-1434. (in Chinese) 